\title{
Laboreal
}

Volume $1 \mathrm{~N}^{0} 1$ | 2005

Varia

\section{Redescubramo-nos na sua experiência : o desafio que nos lança Ivar Oddone}

Redescubrámonos en su experiencia : el reto que nos lanza Ivar Oddone

Redécouvrons-nous dans son expérience : le défi que nous lance Ivar Oddone

Let's rediscover ourselves in their experience: The challenge Ivar Oddone puts

before us

\section{Ricardo Vasconcelos e Marianne Lacomblez}

\section{OpenEdition}

\section{Journals}

\section{Edição electrónica}

URL: http://journals.openedition.org/laboreal/14124

DOI: $10.4000 /$ laboreal. 14124

ISSN: 1646-5237

\section{Editora}

Universidade do Porto

\section{Refêrencia eletrónica}

Ricardo Vasconcelos e Marianne Lacomblez, «Redescubramo-nos na sua experiência : o desafio que nos lança Ivar Oddone ", Laboreal [Online], Volume $1 N^{0} 1$ | 2005, posto online no dia 01 dezembro 2005, consultado o 20 outubro 2019. URL : http://journals.openedition.org/laboreal/14124 ; DOI : 10.4000/laboreal.14124

Este documento foi criado de forma automática no dia 20 outubro 2019.

\section{(c) (†) (8)}

Laboreal está licenciado com uma Licença Creative Commons - Atribuição-NãoComercial 4.0 Internacional. 


\title{
Redescubramo-nos na sua experiência : o desafio que nos lança Ivar Oddone
}

\author{
Redescubrámonos en su experiencia : el reto que nos lanza Ivar Oddone \\ Redécouvrons-nous dans son expérience : le défi que nous lance Ivar Oddone \\ Let's rediscover ourselves in their experience: The challenge Ivar Oddone puts \\ before us
}

Ricardo Vasconcelos e Marianne Lacomblez

\section{NOTA DO EDITOR}

Manuscrito recebido em : Julho/2005

Aceite após peritagem em : Novembro/2005

\section{Um convite}

1 Ivar Oddone e os seus seguidores, entre os quais aqui se destaca Alexandra Re, são, para nós, referências estruturais e incontornáveis. Sob a influência da sua "redescoberta do trabalho operário" - mote da obra com que, há mais de duas décadas se nos apresentaram (Oddone, Re \& Briante, 1981) fomos construindo e reconstruindo uma psicologia do trabalho que nos habituamos a chamar também nossa, porque diferente. Fomos construindo o nosso objecto de estudo, os nossos métodos, a nossa acção, a nossa visão do mundo, do homem, do trabalho.

2 No entanto, muito mais há ainda para redescobrir em Ivar Oddone e Alexandra Re.

3 Tentaremos neste texto relatar esta nossa redescoberta de Oddone e Re, desde os primeiros conceitos, aos objectos, aos métodos, ao seu significado para nós (e para uma nova geração de psicólogos do trabalho portugueses), mas, principalmente, o seu 
significado para uma nova psicologia do trabalho que ajudaram a conceber. Assumimonos assim como uma interface que julgamos necessária entre os autores e o leitor, face à diferença de realidades e de experiências que ainda nos separa. Tentaremos, desta forma, pôr o que em comum possamos ter com ambos ao serviço da mudança, da transformação do ponto de vista do leitor sobre nossa (e, já agora, sobre a sua própria) prática.

O presente texto tem como estrutura de base um seminário sobre "Métodos em Psicologia do Trabalho", apresentado por Oddone e Re (2000) na Faculdade de Psicologia e de Ciências da Educação da Universidade do Porto, estrutura essa que acabou por ser enriquecida com elementos complementares, com o objectivo de melhor enquadrar e ilustrar a sua obra.

Convidamos estão o leitor, a (re)descobrir Ivar Oddone e também Alessandra Re, muitas vezes em discurso directo, num texto em que seremos, não apenas narradores/ tradutores, mas também, inevitavelmente, interpretes, apresentando a nossa leitura dos seus ditos, dos seu escritos e principalmente dos seus feitos, tal qual os fomos descobrindo.

6 É importante chamar desde já a atenção para três conceitos centrais : linguagem, sistema e interface, na esperança de que, no final deste texto, os possamos projectar num horizonte bem diferente, bem mais vasto do que o que neste momento a nossa Imagem do mundo nos impõe.

\section{Um começo}

7 No final dos anos 60, alguns grupos de trabalhadores colocaram-me um problema que eu não sabia resolver - relata Oddone (1999). Eles pediam-me (enquanto médico) informações sobre o risco que as suas condições de trabalho poderiam representar para a sua saúde. Eles consideravam que essas informações poderiam permitir-lhes mudar as suas condições de trabalho.

\footnotetext{
"Quando um acontecimento se produz, altera a estrutura da Imagem. A significação de um acontecimento ou de uma mensagem é a mudança que se produz na Imagem. A maior parte das mensagens atravessam-na sem a quebrar, uma parte acrescenta-lhe especificações, detalhes: aquilo que era vago torna-se mais claro, mais estável. Por vezes uma mensagem quebra uma espécie de núcleo, a estrutura que suporta uma Imagem e toda a coisa muda de forma radical" (Boulding cit in Oddone 1999, p. 1).
}

8 As mensagens que determinaram em Oddone esse fenómeno de reorganização da Imagem, introduzindo um elemento de ruptura na sua forma de enfrentar o problema da saúde (que era aquela do médico tradicional) e mudando de forma radical a Imagem que tinha da saúde e da doença, estão relacionadas com esse pedido a um médico de informações adequadas para melhorar as condições de trabalho. Sentiam-se, nessa altura, ao nível do trabalho industrial, os efeitos do Taylorismo e as respostas de antitaylorismo dos trabalhadores.

9 O pedido dos trabalhadores - continua Oddone (1999) levoume, num primeiro momento, a informar-me sobre textos de medicina do trabalho, mas apenas para me dar conta de que aquilo que encontrara era uma lista de substâncias. Não encontrei nada daquilo que os trabalhadores nos descreviam como condições reais de produção, 
nem sobre a possibilidade de substituir processos poluentes por processos não poluentes. Alguns trabalhadores perguntavam-me mesmo como poderiam ficar com silicose mais rapidamente. Este pedido, aparentemente paradoxal, continha na realidade uma hipótese dissonante em relação à minha imagem médica das doenças devidas ao ambiente construído pelo homem. Eu descobrira de facto que o meu conhecimento tinha uma estrutura racional: Um determinado processo produtivo podia comportar riscos para a saúde, mas esse conhecimento dos riscos possíveis, baseado na literatura médica, garantiria, logicamente para mim, a eliminação das condições de nocividade. Pelo contrário, para os trabalhadores, o problema configurava-se de outro modo. Era a realidade produtiva, com os seus riscos reais, que definia a sua atitude. A credibilidade de uma mudança das condições de trabalho, no contexto específico onde elas se encontravam, era o facto psicologicamente importante, que determinava o seu pedido de saúde. Se a supressão da nocividade não era psicologicamente credível, ficar com silicose (quer dizer, ficar doente) "antecipadamente" significava pelo menos poder sair mais rapidamente de um meio de trabalho inevitavelmente nocivo.

Quando hoje tento reconstruir esse momento de ruptura e de reorganização da minha Imagem em termos de psicologia da saúde - relembra Oddone (1999) entendida como capacidade de "ver" o comportamento dos homens face à saúde e à defesa da saúde, eu revejo, por um lado, os clientes que representam o paciente tradicional, com o pedido de diagnóstico, de prognóstico, de terapêutica e, por outro lado, homens que não me pediam exames nem medicamentos, mas uma utilização do saber médico com o objectivo de modificar as condições de trabalho, de prevenir as doenças ligadas ao ambiente, de adaptar o meio de trabalho ao homem no trabalho.

\section{Um novo modelo científico centrado no homem real}

Num tom ideologicamente carregado que caracterizava a época, Oddone, Re e Briante (1981, p. 45) referiam, com (surpreendente) actualidade: "A ciência tradicional (a "dominante") define como objecto de observação o homem e o seu meio técnico. 0 seu objectivo é, sempre, uma medida objectiva que obtém graças a um método analítico e à utilização de instrumentos emprestados pelos físicos e pelos químicos, por um lado, e pelos médicos e psicólogos por outro. Essa abordagem tradicional comporta a decomposição e a medida, tanto do meio (no sentido restrito do termo) como do homem. O primeiro é decomposto em elementos simples (microclima, poeiras, gazes, fumos) e o segundo - considerado apenas do ponto de vista físico - é reduzido a dados antropométricos, a elementos objectivos."

Do ponto de vista psicológico, os critérios de medida são sempre os mesmos : quer se trate do perfil atitudinal, da carga perceptiva ou do sistema homem-máquina, trata-se, sempre e só, de medir objectivamente variáveis independentes recolhidas graças a um procedimento analítico. $\mathrm{O}$ ambiente apreendido na sua totalidade é decomposto em elementos físicos, biológicos e psicológicos, que, por seu turno, são submetidos a uma nova desagregação. Este processo é tido como capaz de medir os micro-elementos do meio (homem incluído) que, considerados separadamente, são confrontados com valores padrão considerados aceitáveis.

Em substância, medimos mas não avaliamos; a avaliação só intervém num segundo tempo, quando se comparam os valores obtidos pelas medidas com as tabelas-padrão. 
Tira-se dessa comparação uma avaliação de risco ou de não risco, para a qual não se prevê qualquer procedimento de verificação. Este processo é, no fundo, absolutamente análogo ao empregue pelos "gabinetes de métodos" no que diz respeito à organização do trabalho : utilização das mesmas modalidades de decomposição e de medida ; mesma correlação de dados elementares com valores padrão; mesma presunção quanto à possibilidade de definir um só valor (o único valor) cientificamente correcto. Além disso, não se tenta, e isso seria aliás impossível, recompor o todo, isto é, o homem e o seu meio. Preocupámo-nos ainda menos com a forma como os homens "vivem" o conjunto das situações de trabalho nas quais se encontram. Contentámo-nos em decompor para medir, em avaliar todos os micro-elementos e em retirar, destas microavaliações, uma avaliação global. Isto conduz à negação do homem enquanto sujeito de avaliação.

O novo modelo científico que acabou por se impor a Oddone, produzido pela experiência dos homens, caracterizava-se, pelo contrário, por uma abordagem global dos problemas e pela formulação assumida de juízos de valor. Visava transformar o meio de trabalho em benefício do homem, enquanto que o modelo tradicional apenas procurava conhecê-lo (parcialmente). Digamos que esta nova modelização repudiava o homem-médio, não apenas do ponto de vista da sua capacidade de trabalho, mas também do ponto de vista da sua tolerância às situações de nocividade, quer se trate de elementos tóxicos ou de fadiga excessiva, física ou mental. Ela propõe consignar um novo objectivo à investigação médico-psicológica e privilegiar não a medida, mas a avaliação, não os instrumentos mecânicos, mas o julgamento dessa nova entidade que era o grupo homogéneo de trabalhadores, enquanto portador de uma experiência validada colectivamente de uma forma sincrónica e diacrónica. (Oddone, Re \& Briante, 1981).

\section{Tempos, espaços, métodos}

O método não é autónomo - sublinha Re (Oddone \& Re, 2000). O método constrói o objecto da investigação. Os métodos são filhos das hipóteses que me coloco. Eu defino o objecto da minha investigação e, em relação a isso, eu defino os métodos.

16 A psicologia do trabalho tradicional, dominante, não pensava na hipótese de a experiência ou a competência se poder desenvolver em situações desfavoráveis e por isso não a estudava. Não desenvolvia por isso métodos adequados porque não era esse o seu objecto.

Oddone, Re e Briante (1981) formularam então uma hipótese: A competência não estava lá. Era algo que deviam recolher, mas procurando qualquer coisa a mais, procurando uma competência profissional alargada, desenvolvida pelo sujeito e não por todos e que seria uma mediação concreta fundamental para definir as situações, mesmo com os mesmos modelos de ordem geral subjacentes. Quer dizer, havia trabalhadores (como há professores, médicos, militares) que se destacavam entre os seus pares, porque desenvolviam essa capacidade de produzir um conhecimento, que é um conhecimento do contexto, que não está generalizado nem é generalizável. Um contexto que não é simplesmente um espaço, mas também um tempo, que tem uma dimensão temporal. Por isso não o posso conhecer através de um contexto exterior, devo conhecê-lo através do expert, com métodos que me permitam recolher uma parte mais invisível, mais humanizada, mais contextualizada da competência. 

podemos pedir a um sujeito que nos transmita a sua competência. Ele não está em condições de o fazer. Muita gente fala de uma competência implícita, tácita, que não é verbalizada ou verbalizavel. Oddone e Re trabalharam muito sobre uma hipótese que é um pouco diferente : o expert verbaliza a sua competência de forma diferente em função do psicólogo com quem interage, das questões colocadas, dos métodos empregues. Ele toma consciência da parte analógica da sua competência apenas através da relação com o psicólogo, que lhe permite visualizar os esquemas de actividades implícitas. Nessas condições, com o objectivo de transmitir até à possibilidade de "descobrir" o seu comportamento profissional, o expert produz a reformulação linguística de um saber operacional, inicialmente estruturado de forma analógica. A conversão de modalidade analógica em modalidade digital determina uma mudança de estrutura cognitiva no expert. A este nível, o psicólogo, que analisa o trabalho, pode ser visto como um expert de aquisição e de valorização da competência (Re, 1990). Assim, não podemos, não devemos falar de uma competência implícita como algo que o expert tem na sua cabeça e que não diz, mas mais como algo que ele não tem na cabeça mas constrói com o psicólogo. Antes tem modos operatórios, gere os problemas de uma forma analógica, sem ter consciência, sem verbalizar para si mesmo o que faz, ele não o sabe dizer.

O psicólogo está, assim, a pedir ao trabalhador algo que ele não sabe fazer. Então, precisam (trabalhador e psicólogo) de um método que os ajude a construir qualquer coisa que não está lá. É preciso um método para gerir essa transmissão, senão vão obter apenas uma deformação e não uma transmissão. O psicólogo vai ouvir apenas o que o seu interlocutor pensa que ele quer saber. Sem esse controlo metodológico, será inevitavelmente aquele que possui a linguagem técnica que dominará esse processo de tradução da competência analógica em saber digital, seja ele o trabalhador (o expert do domínio) ou o técnico (o informático, por exemplo), que utiliza uma linguagem centrada na tecnologia e não a linguagem da competência. Em qualquer dos casos, há sempre uma perda de potencial de melhoria deste sistema, que deriva da heterogeneidade das linguagens dos elementos que o compõem.

Mas, pelo contrário, podemos representar o espaço de comunicação entre os experts implicados na análise do trabalho como um "não lugar", que vai ser progressivamente transformado em "lugar", através da construção de uma linguagem "comum", que não é nenhuma das linguagens de partida, mas que será a linguagem de chegada (Oddone \& Re, 2000).

Laboreal, Volume $1 \mathrm{~N}^{\circ} 1$ | 2005 
23 A psicologia parte então à procura de condições que lhe permitam favorecer a formalização e a transmissão da experiência profissional e é desse esforço que resultará, após várias tentativas, o método das “instruções ao sósia”, que hoje em dia continua como pano de fundo de diversos trabalhos que visam a formalização da experiência, não só por Oddone e colaboradores, mas também por um conjunto de autores que, de uma forma ou de outra, os seguiram (Clot, 1999, 2001 ; de Vincenti, 1999 ; Duarte, 1998).

\section{À procura de um método : as instruções ao sósia}

Apesar da sua formação médica, Odonne não estava portanto em condições de responder à questão de saúde que lhe tinha sido dirigida pelos trabalhadores, como também não o tornava capaz de "interrogar" as pessoas, de forma adequada, sobre o seu meio de vida e de trabalho. Para o fazer, deveria ter um plano profissional de investigação que lhe permitisse reconstruir a condição de produção e a organização do trabalho que a definia, até a uma especificação suficiente para "ver" o que "via" o trabalhador em situação produtiva.

Precisava antes de tudo de resolver um problema chave : construir uma linguagem que tornasse permeável a interface entre si, como técnico de saúde, e eles, como sujeitos que lhe pediam que gerasse a solução do problema da nocividade do trabalho. Uma primeira tentativa refere Oddone (1999) foi a de tentar reconstruir a representação dos trabalhadores sobre os factores de risco, enquanto conjunto mínimo de conhecimentos do mesmo tipo que os conhecimentos científicos, sem mudar de paradigma, ou seja, em termos de divulgação.

26 A solução passou ainda pela linguagem, pela "competência de utilização" comum a todos, por um guião; pelo material cognitivo mnemotécnico, ligado à linguagem histórico-natural ; por aquilo que, se poderia definir como "aquilo que não podemos não saber".

"Que imagens vêm ao espírito, por associação, quando um sujeito escolhe uma casa? Quais quando pensa numa fábrica? Quais quando pensa em fadiga?". As respostas eram imagens familiares a todos, seja qual for o nível de escolaridade. Daqui derivam os "quatro grupos de factores nocivos" que nos anos 70 foram o instrumento essencial da linguagem da saúde nas fábricas.

28 A casa faz lembrar : temperatura, iluminação, ruído, ventilação, humidade ( $1^{\circ}$ grupo). A fábrica : poeiras, gases, fumos, vapores ( $2^{\circ}$ grupo). A fadiga, dois tipos fundamentais de fadiga : a tradicional, devida à actividade física ( $3^{\circ}$ grupo), outras formas infinitas de fadiga devidas a outras causas que não a actividade muscular, por exemplo, monotonia, ansiedade, repetitividade, ritmos excessivos, responsabilidade ( $4^{\circ}$ grupo).

Assim se conseguiu definir um glossário comum, compreensível por ambos os lados da interface, que servia de base à análise das condições de trabalho a que o sujeito estava exposto. Este modelo dos 4 grupos de factores de risco, foi também retomado mais tarde, como veremos mais à frente.

Um segundo elemento de reorientação da competência no sentido de uma psicologia da saúde caracterizada num sentido ergonómico, verdadeiramente transformador, passou pela consciência reflectida da centralidade dos "locais". Construiu-se então o mapa bruto. Os trabalhadores desenhavam mapas brutos dos seus postos de trabalho, de 
forma grosseira, como um mapa do tesouro. Isto representava a possibilidade de confrontar mapas cognitivos espaciais, que a psicologia conhece bem mas utiliza pouco (Oddone, 1999). Utilizá-los significa descobrir que, sob o seu aspecto grosseiro, os mapas cognitivos revelam uma riqueza notável. Definem-se como brutos pelo significado atribuído ao adjectivo pelo dicionário. "à espera de uma qualquer elaboração formal". A possibilidade de confrontação significava verificação, possibilidade de capacidade crítica, capacidade de distinguir dois lugares distintos.

No entanto, Oddone e a sua equipa foram-se apercebendo de que, apesar do seu grande empenho neste processo, os resultados não eram os desejados. Quando falavam com os trabalhadores, continuava a haver algo que não funcionava. Aperceberam-se de que os trabalhadores o faziam eliminando aquilo que pensavam que os entrevistadores já sabiam, o óbvio ("ce qui va sans dire"," ce qui tombe sous le sens").

Foi na tentativa de ultrapassar os limites do óbvio, que Oddone concebeu o método que baptizou de "método das instruções ao sósia", que consistia em pedir a cada sujeito que desse instruções a um eu-auxiliar, a um sósia. Na sua formulação original (Oddone, Re \& Briante, 1981, p. 57) o pedido era apresentado nos seguintes termos : "Se existisse uma outra pessoa perfeitamente idêntica a ti próprio do ponto de vista físico, como é que tu lhe dirias para se comportar na fábrica, em relação à sua tarefa, aos seus colegas de trabalho, à hierarquia e à organização sindical (ou a outras organizações de trabalhadores) de forma a que ninguém se apercebesse que se tratava de outro que não tu ?". É claro que, com este método, não se recolhe o comportamento real e total do indivíduo, mas a sua imagem, a representação que ele tem do seu próprio comportamento.

Do ponto de vista psicológico, isto é interessante porque obrigava o sujeito a pensar, em detalhe, no que era e no que fazia (chegar cedo, chegar tarde, olhar, falar, conversar com os outros...). Os trabalhadores apercebiam-se sobretudo de que tinham inventado soluções muito importantes, utilizando a experiência para melhorar a saúde.

A equipa de Oddone apercebeu-se então de que, à medida que utilizava o método, não adquiria apenas a possibilidade potencial de se substituír ao trabalhador (nem era esse o objectivo), mas também se apercebia da maneira como poderia melhorar o trabalho, apropriando-se fazendo própria a experiência dos homens.

Significou também que o homem deveria estar no centro do processo. Para o fazer é preciso uma experiência que os autores não tinham. Faltava algo entre o investigadorpsicólogo do trabalho e o sujeito-trabalhador, que representava a fonte fundamental de transformação do trabalho.

Não se trata de uma relação clássica, do tipo "eu vi", "eu estudei”, “ eu descobri”. Tratase de uma relação diferente. Trata-se de um sistema em que os dois sujeitos (investigador e trabalhadores) beneficiam e se transformam progressivamente.

$\mathrm{O}$ centro de gravidade da investigação psicológica desloca-se. Passa do diagnóstico à invenção de um quadro e de um dispositivo onde os implicados podem pensar colectivamente o trabalho para o reorganizar. "A análise do trabalho já não é apenas a fonte da acção, mas um recurso para sustentar uma experiência colectiva de modificação do trabalho por aqueles que o fazem" (Clot, 2001, p. 10). 


\section{Desenvolver a experiência : que presente, que futuro ?} Oddone e Re. A conjuntura histórica é manifestamente diferente : as lutas ideológicas esmoreceram, mudaram de sede, de tom, de protagonistas; o trabalho industrial transformou-se, impulsionado por uma revolução tecnológica muitas vezes desregrada, muitas vezes vista como a solução (em si e por si só) para tudo, solução para a baixa da produtividade, solução para a "garantia" da qualidade ; o trabalho dito manual é cada vez mais também um trabalho menos manual, mais invisível, um trabalho dito cognitivo, de monitorização, de vigilância. Outras formas de trabalho, outras formas de prestação de serviços, vão aos poucos ganhando terreno ao trabalho industrial, ao trabalho "sujo", onde os autores começaram a redescobrir a experiência dos trabalhadores. 70 , Oddone e seus colaboradores começaram a construir em torno dos seus três pilares (linguagem, sistema, interface) e do desenvolvimento da experiência colectiva e individual. Pelo contrário, nunca a natureza dos problemas e dos pedidos sociais, presentes e potenciais, abriu tantas perspectivas de afirmação e de evolução a esta nova psicologia do trabalho.

pode o vivido tornar-se um meio para viver outra coisa diferente ? Esta é uma questão que permanece central para a análise do trabalho actual. Além disso, é também um interessante problema teórico para a psicologia. Oddone "transmitiunos - por exemplo com o método do sósia - a possibilidade de verificar esse fenómeno : o que conta, na observação da actividade vivida, é menos a observação do que a diferença entre as observações; menos a primeira observação do que a segunda que tem a primeira como objecto. 0 que conta é que os sujeitos "observados" no seu trabalho por aquele que intervém, possam tornar-se um meio de viver outras experiências. É assim, e só assim, que amanhece um desenvolvimento subjectivo da experiência vivida : um desenvolvimento da experiência." (Clot, 2001, p. 10).

41 Porquê recolher experiências? E para quê? "Trabalhar, hoje em dia, é muitas vezes fazer face a uma imposição: assumir as suas responsabilidades sem ter responsabilidade efectiva na definição do trabalho, amplamente submetida a objectivos fictícios. Responsabilidades sem responsabilidade : eis uma das maiores separações do trabalho actual." (Idem, p. 11).

42 É implicitamente exigida aos trabalhadores uma disponibilidade psicológica cada vez maior para agir em meios profissionais cada vez mais ambíguos e que, por isso, reclamam que os trabalhadores dêem cada vez mais de si. Esse facto tem consequências : a disponibilidade exigida pressupõe e exige, em contrapartida, um desenvolvimento dos recursos colectivos voltados para a acção. Mas, a organização do trabalho (de qualquer trabalho e não apenas o trabalho industrial), que deveria colocar esses recursos à disposição dos trabalhadores, esquiva-se massivamente a essa missão. Ela não oferece uma disponibilidade comparável àquela que exige. Ela priva os trabalhadores dos meios de exercer as responsabilidades que eles assumem apesar de tudo (Clot, 2001). Ela priva-os da sua experiência e do potencial que esta encerra. 


\section{Linguagem, sistema, interface}

43 Apoiando-se em Winograd e Flores, Oddone (Oddone \& Re, 2000) apresenta uma exploração interessante do óbvio, para além do qual é difícil de passar. Partilhamos coisas sempre através da obvieta, do conjunto de elementos que temos em comum. Se passarmos para além disso, para além dos limites do óbvio, passamos a ter um problema.

44 É em relação a isso que se pode falar de breakdown, de ruptura. Das dificuldades que temos à partida para a comunicação, quando queremos comunicar qualquer coisa que está para além daquilo que temos em comum. É este o aspecto fundamental : Ver para além daquilo que vemos. $O$ que não é fácil, como não é fácil sequer compreender o que isto significa.

A verdade é que foi um pouco isto que Oddone descobriu (se bem que não o tenha descoberto desta forma) quando se encontrava com os trabalhadores, com os técnicos e não compreendia completamente aquilo que diziam. Não compreendia porque via apenas aquilo que conhecia.

"Então refere Oddone (Oddone \& Re, 2000) se aceitarmos o conceito que poderia aqui haver de breakdown, isto é, de um momento no qual a partilha é impossível porque há algo que está para além daquilo que temos em comum, então o problema está relacionado com a divisão entre o domínio da existência e o domínio da descrição. Ou seja, nós conhecemos através do domínio da descrição, já que o domínio da existência é um domínio diferente e, entre os dois, há muitas vezes situações de ruptura.

A forma mais simples de ser claro é estando dentro do discurso que nos dá o sujeito com quem temos uma série de coisas em comum. A linguagem é, por isso, algo que nos chama a atenção para o facto de que o expert que nos interessa, o trabalhador que nos interessa, deve ser aquilo que certo dia os autores apelidaram de "expert-bruto", entendendo-se bruto como algo que é necessário elaborar.

$\mathrm{Na}$ conversa que iniciavam, estavam prestes a elaborar, em conjunto, qualquer coisa que não existia ainda.

Re (1990), em "Psicologia e soggetto esperto", propõe que se analise a relação de continuidade entre o sujeito que investiga e o sujeito investigado (no sentido figurado do termo), como uma escala de consciência reflectida. Isto é, há uma fase na qual o expert e o investigador estão numa situação de simples diálogo e, se o investigador não for capaz de fornecer ao expert os elementos que lhe permitam perceber a expertise bruta e elaborá-la com o investigador, não é possível ultrapassar os limites do óbvio.

Este é o elemento fundamental de tudo o que fazemos. o investigador, o psicólogo do trabalho deve ser capaz de convencer o sujeito de que ele é portador de uma experiência, de uma capacidade, de um plano de comportamento (Miller, Galanter \& Pribam, 1960), que existe de um ponto de vista analógico (já que ele é capaz de o utilizar), mas que não é, de todo, capaz de transmitir. É necessária uma construção conjunta e, recuperando o conceito de linguagem em termos de breakdown, devo partir para a investigação convencido de que há qualquer coisa que está para lá do que nos pode ser transmitido directamente. Se eu conseguir convencer o outro disso, há de haver um momento em que estejamos em condições de ver os elementos que é preciso desenvolver dessa expertise bruta. Vamos produzir qualquer coisa transmissível. 
51 Este é um aspecto muito interessante e que tem a ver com a noção de sistema autopoiético: A partir da cibernética, os autores partem da hipótese de que todos os sistemas (sistema de saúde, de produção automóvel, de ensino) são capazes de se autoregularem com base nos seus resultados positivos e negativos. Devem, no entanto, ser capaz de memorizar esses resultados.

Quando um sistema social é capaz de se auto-regular, torna-se um sistema autopoiético. Isto é, ele responde a toda a estimulação externa e a tudo o que acontece como algo que lhe impõe que se defenda. Ele perdeu a função social e tornou-se um sistema que se serve de feedback para se salvar.

O que interessa aos autores no respeitante à noção de sistema, é o facto de um sistema ser aqui considerado como um conjunto de grupos que são homogéneos no sentido em que têm a mesma linguagem. Os subsistemas que têm a mesma linguagem, uma linguagem homogénea, têm uma obvieta. Eles conseguem compreender-se por que têm a mesma visão do mundo, a mesma linguagem.

Entre estes subsistemas há interfaces, que são caracterizadas pelo facto de serem frequentemente comandadas por um dos seus lados. Por exemplo, na interface médicocidadão é o médico que decide, não há permeabilidade na interface.

À medida que a sociedade se desenvolve, estas e outras interfaces estão em constante evolução. Portanto - e aí está uma função fundamental do psicólogo do trabalho - é necessário optimizar, dominar a permeabilidade concreta das interfaces entre os subgrupos. Esse é, por exemplo, um aspecto ligado com a questão das instruções ao sósia, isto é, há dois grupos que têm linguagens diferentes e cuja interface há que trabalhar.

Isto tem a ver com aquilo que os autores chamam o "dove" (o onde), isto é, o contexto concreto, o local. Porque só aí somos capazes de ter acesso à competência de um sujeito.

\section{Como transferir usabilidade?}

57 Um trabalho que Oddone e Re desenvolveram e que denominaram SEQUIME (Séquence des images-écran), como outros que poderíamos citar, podem ajudar a responder a esta questão da transferência da usabilidade, do potencial de utilização na preparação de projectos de informatização. Tratou-se de uma tentativa (que apenas abordaremos na sua ideologia) de alargar o conceito de interface homem-computador (em termos de simples produto), abarcando o problema da comunicação entre o especialista em informática e o utilizador, de modo a que este último não seja obrigado a utilizar soluções técnicas frequentemente pouco adequadas à sua experiência e ao contexto da sua actividade. Os operadores sabem o que necessitam de ver no ecrã e em que sequência. Se o conseguirem transmitir, depois a transmissão para o programa informático é apenas uma questão técnica. $O$ psicólogo do trabalho tem um papel essencial nessa interface.

Ora, isto remete-nos para outra questão, que tem especificamente a ver com a psicologia e, particularmente, com a psicologia do trabalho - a restituição. Uma restituição que, em psicologia do trabalho, interessa a outros e não apenas a si própria. Ter resultados que transformam, coloca-nos numa situação que tem muito em comum, por exemplo, com a psicoterapia. Temos uma função de prise en charge, de responsabilização. É uma intervenção a longo prazo e que passa sempre por uma 
restituição. Podemos tornar a pessoa capaz de se ver como sujeito activo que pode modificar a sua situação de trabalho.

o papel do psicólogo do trabalho no seio de uma equipa pluridisciplinar é, por outro lado, um papel que tem a ver com o aspecto cognitivo e de memória. Um aspecto essencial é o de considerar a memória, o conhecimento do que aconteceu até este momento em qualquer empresa.

60 A forma na qual o sujeito pede ao técnico para intervir é simples: "queria que informatizasse aquilo que eu faço todos os dias". o que acontece normalmente, é que o informático, num dado momento diz “já percebi”, e a partir daí vai dar um protótipo ao sujeito. Mas o que há que não compreendemos? Não vemos o que o informático compreendeu daquilo que havia na cabeça do sujeito que pediu a informatização. Também não vemos como isso pode ser feito do ponto de vista técnico. Não sei nada de informática. Sei, no entanto, que tem um ecrã que corresponde a páginas ; e páginas eu conheço. No momento em que passo a informação ao informático passamos a ter qualquer coisa em comum.

\section{Da usabilidade à utilidade}

61 Falemos de qualquer coisa mais visível do que até aqui. Tentemos integrar os princípios gerais apresentados, no contexto que os gerou, nos avanços e recuos que lhes dão sentido e que alimentam o seu desenvolvimento - a acção, a intervenção concreta, a melhoria dos homens e dos sistemas em que se movimentam.

62 O que significa uma abordagem ergonómica para Oddone e Re ? Para que serve ? O que dá ? Quais as situações que se pode derivar dela?

63 Tentar-se-á apresentar outras imagens, que enriqueçam e complementem aquelas que vimos a propósito das investigações que Oddone, Re e Briante (1981) relatam em "Redécouvrir l'expérience ouvrière", feito na industria. Vejamos então alguns trabalhos feitos sobre a tecnologia do computador.

\section{Acompetência : tecnicizar a nossa para preservar a dos outros}

Os pedidos de hoje em dia são pedidos complexos, que mexem com todas as dimensões da intervenção de que falámos. Não podemos trabalhar sozinhos. Precisamos de nos inserir num grupo de trabalho que abarca competências diferentes. Muitas vezes, quando trabalho com outros profissionais - refere Re (Oddone \& Re, 2000) sou capaz de ver a sua competência, mas eles nem sempre são capazes de ver a minha. Eles têm sempre dificuldade em identificar a minha competência enquanto psicóloga.

Em segundo lugar, eles trabalham cada um por si, mas apenas o psicólogo tem os instrumentos para criar um grupo de trabalho integrado para a projecção de uma nova situação de trabalho a sua complexidade.

Assim, o psicólogo pode desenvolver dois tipos de competência : (i) uma competência directa, para analisar a organização, as actividades; (ii) uma competência para construir o grupo de projecto - para o gerir de uma forma integrada. 
67 Re teve assim que enfrentar um paradoxo, tinha que tecnicizar a sua competência, face a instrumentos que não são instrumentos clássicos do psicólogo, com o objectivo de evitar que se tecnicizasse a competência dos outros, porque, sem o psicólogo, o informático intervém e produz-se uma tecnicização da competência do operador. Isto é, a interface entre o operador e o informático é dominado pelo informático. A linguagem informática torna-se a linguagem dominante. Neste contexto, o psicólogo é como um guardião que pode permitir ao pedido social (no sentido da criação de uma dinâmica de mudança, como na psicologia clínica) sua explicitação face a todas as competências envolvidas.

68 Para muitos, activar uma mudança significa, simplesmente, modificar a mesa, os instrumentos, o ambiente físico. Para o psicólogo-ergónomo, activar a mudança é sempre, para além disso, activar uma dinâmica de grupos sociais na organização. E isso é de facto difícil e só é possível a longo prazo.

69 Re (Oddone \& Re, 2000), relata um pedido da parte de um serviço de urgência hospitalar que alegava que havia utentes a mais no serviço. Havia grandes filas de espera, grande volume de trabalho, o que levava a que os profissionais não pudessem trabalhar em condições.

70 A equipa de Re começou então esse trabalho com uma acção de formação onde procurava o saber de referência no interior da organização, com os enfermeiros, os responsáveis de sector, os psicólogos do hospital, etc. Tentavam assim reconstruir um percurso completo de um paciente num outro Serviço para não terem dificuldades com o Serviço onde iriam efectivamente intervir. Entrevistaram ainda todos os enfermeiros do departamento de urgência e os auxiliares de acção médica, recorrendo numa segunda fase a um conjunto de instrumentos mais específicos. Obtiveram deste modo muita informação e, desde logo, a triagem (a recepção dos doentes) foi uma função que apareceu como crítica e fundamental, em termos da dificuldade de ordenar os pacientes de acordo com a gravidade da urgência.

71 A partir desse trabalho, a equipa de investigação inverteu a sua relação com os enfermeiros e foram os próprios investigadores que tentaram simular a realização do trabalho. Eram estes que diziam, em pormenor, aos enfermeiros, o que devia ser feito. Foi relativamente fácil simular a primeira meia hora após a chegada do doente. Depois disso, a tarefa foi difícil porque descobriram que os enfermeiros não tinham “memórias", isto é, no fim da manhã eles já não se lembravam dos pacientes que haviam recebido nessa manhã. Porque a situação era de tal modo caótica que era difícil memorizar os casos.

72 Nessa altura, tiveram necessidade de fixar um objecto da investigação, para conduzir a análise da produtividade e da qualidade do serviço. Pensaram então que "o homem no centro" - o seu slogan - seria, neste caso, o paciente.

73 Nos aviões, há a caixa negra que regista tudo - o dito, o escrito, os indicadores, os tempos, etc. Aqui, a caixa negra era o paciente, era o percurso do paciente desde que entrava na organização até ao final do percurso, à saída. Assim, era ele o fio condutor para começar a produzir a visibilidade do sistema.

74 Naquele seminário/acção de formação inicial com que se iniciou este trabalho no Serviço de Urgência, o pessoal responsável por aquele departamento dizia que "não era possível". Quando a equipa de Re apresentou o seu projecto de análise, o responsável pela qualidade, o responsável pela planificação, pelo pessoal, diziam que "era 
impossível". E diziam-no apoiando-se num standard, num padrão de qualidade que tinham já projectado para todos os departamentos de urgência. A questão chave aqui é que deviam pôr a hipótese de que há um standard de qualidade sobre o qual trabalham que não é o ideal. mos pouco pessoal", mas, com efeito, a equipa de investigação/inter que o sistema de estabelecimento da qualidade do meio era discutível. Um problema era, por exemplo, que as informações eram guardadas apenas em memória. Não havia uma memória escrita. Há datas, mas não espaço para escrever informações suplementares, o que torna difícil gerir o paciente que espera a consulta médica, que espera uma radiografia, que volta do especialista, que já passou uma vez mas que deve voltar a ver o médico, etc. É impossível gerar uma memória. Acontece assim muitas vezes que não se sabe onde está determinado paciente... constatando que as pessoas vêem a situação de trabalho de forma muito diferente. Para a enfermeira, a imagem são doentes em risco. A enfermeira gere a informação, o estado do paciente, os espaços, as disponibilidades ou indisponibilidades... Para o paciente, a qualidade que percebe não está ligada ao que recebe em termos de prestação de serviços de saúde ou de competência. Está antes muitas vezes ligada aos elementos que sentem com maior intensidade. Por exemplo, se ele passa 4 horas na sala de espera, se teve que esperar $n$ tempo pela radiografia, o que ele diz é "Ninguém falou comigo... ninguém se preocupou comigo..."

que produziu então essa intervenção? Produziu um pedido do arquitecto, que deveria projectar o novo hospital, para simular o percurso do paciente no novo hospital, para visualizar todas as dimensões que podem acumular-se, para dar uma resposta de qualidade ou uma resposta problemática.

81 O psicólogo do trabalho deve visualizar todas as interfaces que o percurso do indivíduo activa no sistema (físicas, cognitivas, de relação, procedimentos, organização) para traduzir a sua análise em linhas orientadoras, que podem propor para fazer um projecto técnico centrado no paciente e, de uma forma indirecta, sobre todos os operadores que intervêm sobre o paciente. 0 layout da triagem, da sala de cirurgia,...

Muitas vezes trabalha-se para produzir um programa de computador ou qualquer outro instrumento que seja visível, mas há algo de mais importante que é o valor de utilização de uma investigação. Não é só um problema de usabilidade, mas principalmente de 
utilidade, do valor de mudança que ela encerra. A restituição dessa primeira análise, produziu uma primeira mobilização dos enfermeiros, uma crença na mudança e este deve ser o primeiro passo para não criar uma ilusão de que os técnicos podem resolver todos os problemas de projecto. Não são só os standards, os valores-padrão (como a altura das mesas, o tipo de ecrã, as cadeiras) que nos podem ajudar, mas também as particularidades do contexto.

83 A simulação é um recurso metodológico poderosíssimo. Nas instruções ao sósia o objectivo é o de sermos capazes de simular o trabalho de um outro. Neste projecto o objectivo era o de simular o comportamento de um sistema sem o "embelezar", isto é, sem eliminar tudo aquilo que foge à prescrição ou que "não deveria existir", tudo o que é imprevisto, ocasional.

Quando nos pedem para descrevermos uma situação de trabalho, há habitualmente uma limpeza do que é acidental. Pelo contrário - nota Re (Oddone \& Re, 2000) se formos capazes de simular um sistema tal qual ele é na sua actuação quotidiana, torna-se possível trabalhar com as pessoas para avaliar e reprojectar as situações. E este já não é um projecto feito "à escala". Não é "tomem lá o programa para memorizar o percurso do paciente". É antes "como podemos estruturar essas informações ?"; "como podemos apresenta-las num ecrã ?". Mas não é um problema do programa. É um problema da análise da actividade. A actividade, os objectos são centrais.

Há um método possível hoje em dia, porque a equipa de Re reconstituiu o percurso do paciente a partir de frases das enfermeiras que continham desvios. A restituição colectiva permite desenvolver essa análise e atravessar a linha entre a análise e o projectar de um sistema, muitas vezes com um custo muito baixo. Não se trata de saber "que novos instrumentos?", mas de conhecer procedimentos quotidianos e de fazer com que deixem de estar ligados à iniciativa de uma pessoa, torna-los algo que é de todos.

Será possível, no plano da análise do trabalho, definir modelos de simulação para sistemas sociais, para organizações?

Se formos capazes de simular um sistema organizado, talvez tenhamos métodos capazes de gerar a produtividade e a qualidade.

Muitas vezes os simuladores técnicos traduzidos para sistemas sociais são os mais bem aceites pelas empresas, o que é uma ilusão, porque simulam algo que não funciona assim. Para simular um sistema social remata Re (Oddone \& Re, 2000) devemos ser capazes de focalizar um dado sistema, em profundidade, sem generalizar, mas de uma forma "idiográfica" e etnográfica (se bem que a etnografia será eventualmente insuficiente para produzir a mudança, dificilmente activando o poder social no sentido da mudança).

\section{O Sistema de Informação Concreta}

89 Conhecemos Oddone e a sua equipa através das suas reflexões sobre as questões da saúde e do ambiente de trabalho, utilizando os trabalhadores como os sujeitos, os actores fundamentais. Foi a partir daí que começaram a colocar a questão de desenvolver uma investigação-acção, que, pela sua filosofia, duração e visibilidade, merece aqui um destaque particular. Trata-se de um projecto que procurava possibilitar a prevenção da doença devida ao ambiente, a partir de um aspecto 
particular do ambiente : as empresas. As empresas são, do ponto de vista científico, laboratórios que permitem descobrir relações entre os próprios laboratórios e a saúde dos homens.

Começamos por nos colocar o problema : “O que é a prevenção ?" - relata Oddone (Oddone \& Re, 2000) Não devemos confundir a prevenção real com a palavra. A prevenção de doenças é algo de que se fala há muito tempo, mas que não temos sido capazes de realizar As doenças que podemos certamente eliminar, as doenças elimináveis são, certamente, devidas àquilo que podemos designar como "o ambiente construído pelos homens", porque se o construirmos de outro modo não teremos a doença. A partir daí, Oddone e a sua equipa tiveram a possibilidade de conceber um sistema (no sentido que aqui interessa: um sistema composto por subsistemas e utilizando uma dada linguagem).

91 Há cerca de 20 anos, a partir da resposta a um pedido de uma sociedade de seguros mútua, desencadeou-se então um projecto piloto para a transformação de uma instituição de saúde, com base territorial na região de "Bouches-du-Rhône", em França. Desenvolveu-se assim uma investigação na área da psicologia da organização da saúde, com base ergonómica, daí resultando um projecto de organização da saúde : o Sistema de Informação Concreta (SIC).

O objectivo da intervenção de Oddone era, deste modo, o de transformar a organização curativa existente, numa organização capaz de identificar (para poder eliminar) as doenças seguramente elimináveis, enquanto doenças devidas ao ambiente construído. $\mathrm{E}$ propunha-se fazê-lo definindo os riscos prioritários, considerados índices prioritários da saúde ; criando um percurso de informação sobre a saúde individual ; reunindo as informações individuais para obter uma representação da saúde colectiva; informatizando o sistema; difundindo os resultados como terminais de um serviço ajustado, estruturado de forma a permitir à comunidade municipal a avaliação da organização da saúde e a sua consequente modificação.

o "onde", dimensão central de qualquer intervenção, foi aquilo que se poderia equiparar a um "centro de saúde" gerido por uma organização de seguros mútua. Um centro de saúde que pode ser considerado como privado no sentido em que gere a saúde (para exigências não hospitalares) dos aderentes à sociedade de seguros mútua, com uma organização autónoma, com secretárias, médicos generalistas, médicos especialistas, um laboratório.

No quadro da actividade usual do médico neste contexto, o SIC representa uma actividade integrada na sua actividade habitual de médico generalista, de médico de família.

Neste caso, os sujeitos fundamentais são os médicos. Já não são os operários na cadeia de montagem, mas os médicos generalistas. Eles podem ser actores de prevenção, mesmo não sendo médicos do trabalho. Não podemos separar o "eu trabalhador" do "eu homem".

O médico generalista é a interface mais rica, mas também a mais isolada. $O$ médico não tem a credibilidade para modificar as situações de perigo. Era possível para o psicólogo do trabalho construir uma mudança que permitisse que experts isolados trabalhassem em conjunto, através de um sistema de informação - foi isso que procurámos, refere Oddone (Oddone \& Re, 2000). 
Começamos então a utilizar as instruções ao sósia no sentido de recuperar a experiência do médico, definindo um percurso diagnóstico diferente, que era construído sobretudo do seguinte ponto de vista : o médico tinha sempre a suposição de que a doença dependia do ambiente. A partir daí desenvolvia um percurso diagnóstico, uma abordagem. 0 médico, com base em regras instauradas no sistema, levanta a suposição de que a doença possa estar ligada ao trabalho ou ao ambiente e, a partir daí, nós ajudamos o médico, através de uma entrevista, de um questionamento feito por uma secretária, treinada de uma forma bastante precisa para essa função.

A declaração do médico, que pode ser substituída pela declaração do próprio sujeito que quer saber se a sua saúde está em risco do ponto de vista das agressões ambientais, dá lugar à criação de uma lista de sujeitos presumivelmente em risco.

Quando um cliente se dirige ao centro de saúde para uma visita usual, se estiver assinalada para ele uma situação de "presunção de risco", põe-se em marcha um ciclo caracterizado pelo percurso : médico, secretária, cartógrafo, médico. Um percurso que a informação, considerada central no sistema, traça e que o psicólogo da saúde conduz do ponto de vista dos procedimentos. Aquele que o gere, do ponto de vista operacional, através das pessoas implicadas, em particular dos médicos generalistas, é uma figura nova na organização da saúde - o cartógrafo. Ele é o gestor de uma intervenção de ergonomia cognitiva, controlada pelo psicólogo, visando a recuperação da experiência dos sujeitos implicados, em particular, os conhecimentos do cliente sobre o seu micromeio de vida e de trabalho.

100 A partir daqui, o médico passa a ter a possibilidade de utilizar qualquer coisa, que, geralmente, não pode utilizar.

101 Começámos a pensar o que é que o médico generalista pode saber ou precisar de saber sobre o paciente (anamnese), mas a coisa mais importante - o ponto de vista do trabalho - ele não pode conhecer, é muito difícil. Iríamos tentar facilitar-lhe o acesso a essa informação de uma forma sistematizada e integrada.

\section{O ciclo do SIC}

102 Depois da sinalização do médico que dá origem ao percurso, passa-se ao inquérito por uma secretária, que preenche a ficha individual de riscos e a ficha do posto de trabalho. Para recolher as informações necessárias, a secretária segue um procedimento definido e periodicamente verificado pelo psicólogo com os operadores interessados. O procedimento utiliza o modelo dos quatro grupos de factores nocivos (a que se fez referência mais atrás neste texto, aquando da apresentação da técnica das instruções ao sósia) e as informações já acumuladas no cadastro de situações de risco do SIC, na tentativa de criar uma linguagem comum.

103 A ficha individual de riscos, informatizada, é composta por 4 áreas: (i) a primeira permite identificar o sujeito (o nome é apenas visível para o médico que o trata) ; (ii) a segunda identifica o posto de trabalho e os riscos eventuais por exposição; (iii) a terceira precisa os riscos de doenças e os agentes agressores (atteintes) eventualmente presentes. Estas três partes são rigidamente codificadas enquanto que (iv) uma quarta parte, chamada "folha de acompanhamento", contém todas as restantes informações (não trabalhadas de forma codificada nas outras áreas) sobre o sujeito e sobre as 
condições de riscos, já que se presume que elas possam ter interesse. O objectivo é o de facilitar uma observação, gravada, "aberta", não definida a priori pela codificação.

A ficha do posto de trabalho representa a base da anamnese ambiental, concreta, utilizável para estabelecer uma ligação eventual entre dano e ambiente. 0 posto de trabalho é identificado através de três elementos : o "2 x 2", o "OQF" e a "especificidade local".

- 0 "2 metros por 2 metros" define o contexto espacial concreto no qual um sujeito trabalha (pode haver mais do que um por trabalhador);

- O "O Que Faz" é aquilo que o sujeito faz verdadeiramente no

- seu posto de trabalho (a tarefa conotada de forma adequada);

- A "especificidade local" identifica se a actividade de trabalho, o processo, tem características específicas, positivas ou negativas, no que respeita ao risco em relação às actividades de trabalho do mesmo tipo.

A avaliação do risco e/ou do dano na saúde do indivíduo, ou seja, a necessidade de exames, o significado dos resultados, a eventual declaração de doença profissional, é da competência do médico generalista. 0 mesmo que assinalara a suspeita de risco e que a verifica com base nas informações (ambientais, clínicas e de laboratório).

O cartógrafo constrói arquivos dos postos de trabalho em risco. 0 termo que o qualifica profissionalmente deriva do seu dever de produzir cartas/mapas de risco. As cartas são construídas desde baixo, por aposição, sendo cada novo caso acrescentado aos casos já conhecidos. As cartas são utilizadas, juntamente com uma parte do material das fichas individuais, para a construção de um painel municipal de riscos composto por :

A. Uma carta topográfica do município, com a notação dos locais em risco ;

B. Quatro colunas relativas aos riscos prioritários :

1. 1. lista numérica das pessoas em risco para cada um dos riscos prioritários (estimativa);

2. lista numérica das pessoas em risco (conhecimento documentado no SIC);

3. lista numérica dos danos (estimativa);

4. lista numérica dos danos (conhecimento documentado no SIC).

O painel municipal de riscos é actualizado periodicamente e utilizado pelos três protagonistas do Sistema de Informação Concreta: os cidadãos, os médicos e o presidente da autarquia. Este painel representa um dos dois pólos (o outro é representado pelas fichas individuais) de um sistema ergonómico (adaptado e transformador) com uma forte possibilidade de função cibernética, no sentido em que as informações tornam possível o controlo do território para verificar a melhoria da saúde para a qual tende o sistema.

\section{Uma acção-investigação em ergonomia da saúde}

A organização da saúde comporta a identificação dos "actores" fundamentais da organização, actuais e/ou potenciais, e as interfaces de contacto.

Oddone utilizou um esquema que permite a confrontação entre situações diferentes. Há sempre três elementos presentes, no quadro do território de um município, no cenário da organização da saúde: os cidadãos, os médicos generalistas e o presidente da autarquia. 0 triângulo de base para o Sistema de Informação Concreta. 
110 A qualidade de cidadão é comum a todos : é o sujeito que tem o problema da sua própria saúde. Todos têm a qualidade de cidadãos, incluindo os componentes dos segundo e terceiro grupos. $\mathrm{O}$ segundo grupo - o dos médicos generalistas - tem uma função social particular : "avaliar" a saúde dos cidadãos (e agir em consequência). O terceiro grupo, representado emblematicamente pelo presidente da autarquia, compreende aqueles que, na sociedade, têm a função de gerir o território municipal, o ambiente construído, também em função da saúde.

111 O estudo das relações entre esses actores pressupõe a hipótese de que há uma homogeneidade de linguagem no interior desses três grupos e uma heterogeneidade entre grupos. Consequentemente, para o psicólogo, é de um interesse notável o estudo das interfaces de comunicação entre esses grupos. Em primeiro lugar, para verificar quais são apenas potenciais e quais são actuais. Por outro lado, há interesse em saber se há prevalências numa das áreas que se interligam; se a permeabilidade é válida nos dois sentidos ; se, no conjunto, a perda de informação na passagem é aceitável. 0 estado destas interfaces determina e define a eficácia das linguagens procedimentais : a estrutura dos dossiers médicos, o procedimento de interrogação anamnésico e as categorias concretas de suporte, os códigos de classificação de doenças, as linguagens de memorização de elementos de referência. O conjunto complexo, em geral confuso, muitas vezes obsoleto, por vezes inadequado, das linguagens da saúde...

De entre as interfaces possíveis entre os três grupos, apenas uma está geralmente activa : a interface entre o cidadão singular e o médico generalista correspondente. $\mathrm{Na}$ situação especial dos dois municípios nos quais Oddone trabalhou, em França, onde as diferenciações formais dos serviços de saúde periféricos são muito amplas, a sociedade de seguros mútua desempenhou um papel fundamental para a definição da dinâmica do triângulo cidadão - médico - presidente da autarquia.

113 A nova função activada - a do cartógrafo - desempenha o papel essencial da gestão operacional das interfaces. Neste sentido, a importância da linguagem revelou-se determinante para a partilha de categorias e de estratégias, sobretudo de procedimentos ajustados e participativos. Todo o percurso de informação, desde o momento do nascimento da suspeita até ao conhecimento do risco "de" reconhecido (doença, dano consecutivo ao risco "por"), foi reconstruído com o pessoal paramédico e sobretudo com os médicos.

114 Foram estudados todos os lados do triângulo aos quais correspondem as interfaces, com particular atenção para aquela que se encontra entre o médico generalista e o cliente que foi objecto de investigação com base numa abordagem definida pela equipa como "plano quotidiano de integração". Simulou-se separadamente o comportamento do médico generalista e do cliente, para avaliar incongruências entre os dois planos, as duas linguagens e a permeabilidade da interface. 0 objectivo era a construção do menor denominador comum de integração entre os dois planos de comportamento.

Todos os três lados foram activados, ainda que em medidas diferentes. A activação das interfaces entre o presidente da autarquia e os médicos generalistas e entre o presidente do município e os cidadãos, determinou a criação de um observatório Municipal da Saúde gerido pela Câmara Municipal, que passou a assegurar a difusão dos dados produzidos pelo sistema de informação concreta junto dos médicos exteriores ao SIC e dos cidadãos. 
116 A síntese desses dados é representada pelo painel municipal de riscos, que, de forma actualizada responde às questões: (a) Onde estão os riscos prioritários? (b) Quantos estão expostos a esses riscos? (c) Quantos são os lesados?

\section{Que resultados?}


dados, mas garantir a todos a sua disponibilidade. A qualidade de trabalho do médico é definida pelo processo de partilha dos procedimentos, dos resultados e das inovações. Os procedimentos dos médicos são visíveis, partilhados, formalizados, pelo que o "modelo médio", o padrão, é mais rico e tende a enriquecer-se progessivamente.

Particularmente, o que mudou foi a valência da dupla médico generalista - cliente, que assume a função de motor de influência do sistema.

A inovação fundamental : a qualidade da anamnese. A inovação é a de complementar a anamnese através de precedentes patológicos dos "pais ambientais". A reconstrução da anamnese do sujeito é, por outro lado, reforçada pela memorização do perfil patológico. o médico generalista, médico de família, tem uma carta/mapa mental dos clientes singulares, o que representa um verdadeiro perfil patológico. É uma memória que não está quase nunca escrita, mas ansiosa por enquadrar os sintomas do cliente num contexto de probabilidade definido. O perfil patológico, que compreende o risco ambiental, redefine a anamnese e torna-se uma outra modalidade de classificação, diferente das modalidades tradicionais. As mudanças são estudadas rigorosamente não apenas ao nível do Sistema de Informação Concreta, mas por ondas de choque que se repercutem sobre toda a actividade médica do generalista. Noutros termos, o metamodelo profissional é influenciado pelos procedimentos ligados ao SIC, também no aspecto curativo.

\section{SIC - Sintetizando, Integrando, Compreendendo}

Após o alerta do médico ou do próprio paciente, a secretária recolhe a percepção do risco ("eu acho que posso estar exposto ao risco x..."). Ela regista onde o paciente trabalha, o seu posto de trabalho, o que ele faz, a sua actividade e a especificidade local.

O cartógrafo elabora essa situação no que respeita ao risco. Ele é um expert da relação entre a tecnologia e a saúde, que retoma as informações dadas e, a partir do seu conhecimento sobre bases de dados, sobre arquivos, sobre leis, sobre experts, ele passa ao médico generalista a suposição de que poderá haver um risco, a informação acerca do conhecimento prévio da comunidade científica ou profissional sobre os riscos.

Quando o sujeito chega ao médico generalista, esse médico já tem algo que foi construído para ele e que ele não tinha antes do ponto de vista da organização da informação e da memória. Ele tem já uma nova forma de investigação. Há estudos de etologia que sublinham o facto de os animais (como os homens) explorarem o ambiente procurando qualquer coisa. Não olham indiferentemente para tudo, não ouvem tudo, não cheiram tudo. Muitas vezes o psicólogo do trabalho questiona-se porquê não percebemos todos os detalhes do ambiente, falamos de filtros. Eu não vejo o detalhe porque procuro algo específico.

Deste modo, os médicos também não memorizam o paciente, memorizam o diferente, $o$ não habitual, esquecendo completamente o resto. Memorizam o caso, o caso excepcional. É uma posição activa de investigação.

Por isso achamos interessante estudar uma memória de trabalho que está relacionada com a performance, que orienta a capacidade, a competência profissional.

Essa investigação prévia permite ao médico generalista procurar qualquer coisa que não procurava antes porque era inútil, ele não podia fazer nada. 
Ele vai procurar uma suspeita de risco de agressão (atteinte) num paciente que está ainda numa fase em que os efeitos do agente nocivo ainda não são evidentes. Isto permite ao médico generalista procurar os sujeitos que podem estar expostos e intervir de uma forma muito precoce.

No final do percurso, há então duas bases de dados, dois arquivos : (i) de um lado, há a história do sujeito, a sua história profissional, com os riscos; (ii) de outro lado há o painel municipal de riscos, isto é, no plano municipal, existem dados.

137 Há uma saída do sistema de homens que têm uma história profissional conhecida e tudo o que diz respeito à exposição a riscos para a sua própria saúde. De outro lado há um município que conhece o seu próprio território, do ponto de vista do conhecimento da existência de situações de perigo para os seus habitantes.

138 Não: Oddone e a sua equipa não construiram novas informações. Eram coisas que existiam em algo que não era um sistema. Eram actores que não se conheciam. E o que é interessante é que esse sistema se tornou o motor de um sistema mais alargado que englobou os inspectores do trabalho, que descobriram que havia um conjunto de informações preciosas para o seu próprio trabalho. Descobriram que havia uma lista de pessoas, já reconhecidas enquanto portadoras de uma doença profissional, que foram retomadas para detectar novas situações de risco.

139 Também médicos do trabalho utilizaram este sistema de informação, que se expande em relação a novos actores que contribuem para o enriquecimento da base de conhecimentos.

140 Assim, encontrou-se aí o problema do percurso, o problema de um psicólogo que trabalha para focalizar num sujeito singular toda a potencialidade existente numa comunidade, mas que normalmente não é utilizada, a não ser em termos gerais. Aqui ela é focalizada sobre um sujeito particular. São diversos subsistemas que se melhoram na sua capacidade de se integrarem.

Trata-se do valor heurístico de utilizar o percurso de um sujeito para construir, em torno de si, um sistema e para produzir nesse sistema uma flexibilidade, uma capacidade de se focalizar sobre as exigências desse indivíduo e de se integrar, ou seja, de utilizar todos os seus recursos (antes distribuídos) para ter a melhor prestação face ao sujeito.

\section{Reflexões e desafios}

\section{Reflexões e desafios para uma democracia cognitiva}

142 No período em que escrevemos o "Redécouvrir l'expérience ouvrière" - lembra Oddone (Oddone \& Re, 2000) inventámos a classificação de quatro factores fundamentais do ponto de vista da doença, partindo do problema do significado pessoal atribuído pelos trabalhadores àquilo que designávamos como "agentes nocivos". Se ao nível da interface entre mim e o outro sujeito não passa nada, é praticamente impossível de saber se o sujeito está exposto a algo nocivo.

143 Após diversas tentativas, Oddone apercebeu-se de que a medicina do trabalho tem em conta, primordialmente, os agentes da doença (sílica, por exemplo). Por outro lado, é muito difícil saber se ela existe num determinado meio. Uma coisa é o agente tóxico, outra coisa é saber onde se encontra, em que concentração, quem está exposto a ele... 
144 O representante do poder local pouco sabe da nocividade do ambiente. O médico generalista também poucos meios tem, naturalmente, para o saber. $\mathrm{E}$ os cidadãos ? Cada um conhece, pelo menos, as condições de risco a que está sujeito, é muito provável que as conheça. Mas estas são informações que quase nunca são partilhadas e que são dificilmente partilháveis.

Oddone pensou então no que poderia significar uma democracia cognitiva, isto é, ter como hipótese que o conhecimento de um território é um aspecto psicológico. Cada um dos sujeitos conhece uma parte, mas ninguém tem conhecimento completo da realidade. Pode-se então tentar reunir esses conhecimentos parciais. Foi essa a sua hipótese de partida.

146 Assim, tendo uma hipótese, pode começar-se a pensar em técnicas, em métodos para satisfazer essa hipótese.

147 Criou-se um Sistema de Informação Concreta, que, pouco a pouco, a partir da suposição e dos resultados do percurso diagnóstico para verificar a suposição, cria um conhecimento sobre as causas de doença eliminável que existem num determinado território.

148 A abordagem é aquela em que se baseiam as instruções ao sósia. Cada sujeito, no seu local de trabalho, conhece todos os detalhes (condições de trabalho actuais e passadas, suas e dos seus antecessores). Tentou-se produzir técnicas e métodos para restituir ao sujeito, ao cidadão, todas as suas memórias, todo o seu conhecimento.

149 O que se fez então ? Modificou-se o conceito de diagnóstico. O diagnóstico passa a ter sempre como suposição que há no ambiente uma causa de doença. Começou-se a distinguir, do ponto de vista do risco, o risco "por" e o risco "de". 0 risco por é o agente que pode produzir uma doença e o risco de é o risco de uma doença que o sujeito pode demonstrar ter.

150 Criou-se uma linguagem comum.

151 O triângulo médico generalista - poder - cidadão é um sistema e é uma organização do trabalho, invisível, mas existente e que se pode em certa medida transformar.

152 Há imensos sistemas potenciais que o psicólogo do trabalho pode explorar. No hospital, por exemplo, são geralmente conhecidas as doenças que caracterizam o território, nem se age, nem se pensa nas formas de as eliminar.

\section{Por uma memória do trabalho centrada no homem}

Por que se interessa o psicólogo do trabalho? Qual a sua espe cificidade? Os problemas do homem no trabalho e a forma como o sujeito os memoriza - é esse, para Oddone (Oddone \& Re, 2000), o objecto de estudo e de intervenção do psicólogo do trabalho.

154 A memória é o elemento fundamental para que um sistema se possa auto-regular. É preciso criar em qualquer sistema, mecanismos de informação válidos. Estudar o homem no trabalho, estudar a memorização do seu trabalho é um elemento fundamental. Não há nenhum campo profissional, científico que se interesse por isto.

155 O papel do psicólogo do trabalho, no SIC era o de criar essa memória em função do objectivo do SIC.

156 Quando se fala de uma memória de uma organização, encontra-se por vezes uma memória que interessa ao empresário, mas não numa memória que interessa ao homem 
ou que se interesse pelo homem. O que Oddone descobriu e o que o levou a fazer as instruções ao sósia foi o facto de se aperceber de que toda a gente se interessava pelos operadores, mas que não havia nem uma hipótese, nem uma técnica, que pudesse permitir a reconstrução do percurso de vida de um trabalhador de um ponto de vista profissional. Eliminava-se assim, de uma forma clara, a experiência. Em relação ao médico, por exemplo, não havia qualquer documento válido, que permitisse recuperar a sua memória.

Conseguiu-se, com o SIC, prolongar o presente dos sujeitos, dando-lhes a capacidade de utilizar tudo aquilo que fizeram como algo que possui uma qualidade especial (um pouco como a qualidade das instruções ao sósia), isto é, a qualidade de possibilitar a repetição daquilo que se diz, mas não em palavras, mas em actos, em gestos.

médico não tem normalmente a memória de um percurso, como os enfermeiros também não a têm.

Oddone e a sua equipa reconstruíram, com o médico, a forma de memorizar. Construíram uma forma de memorizar que é a mesma para todos os médicos do grupo. Logo, eles passaram a ter uma linguagem comum. Tornaram os médicos conscientes do potencial dessa memória, conscientes da vantagem de serem médicos diferentes dos outros médicos.

Apercebemo-nos, ao longo de 20 anos - remata Oddone (Oddone \& Re, 2000) de que tudo o que tem a ver com o homem que trabalha é trabalho do psicólogo do trabalho. Em certa medida, ele tem a seu cargo a construção dos procedimentos mais válidos, mas não no sentido do "one best way" de Taylor. Há tantos "best ways", quanto sujeitos. 0 psicólogo do trabalho deve saber que há essa possibilidade e não deve projectar sobre o segundo a forma de trabalhar do primeiro.

\section{Ferramentas para a liberdade}

O que há a fazer com a psicologia do trabalho e não apenas com a saúde ?

que é difícil de pôr em evidência é que Oddone mudou os homens, mudou algo que estava na cabeça dos homens, dos médicos. É esse o papel do psicólogo do trabalho: melhorar o sujeito e as suas condições. Se não melhorar as condições será quase uma produção de escravos.

Oddone mudou os homens utilizando o seu potencial. E isto é bem mais difícil do que possa parecer. Por isso é que a linguagem é um aspecto fundamental. O risco - alerta Oddone (Oddone \& Re, 2000) é o de, depois de tudo o que aqui viram, recuperarem a linguagem que usavam antes, e tudo isto desaparece. Podem ficar algumas coisas, algumas imagens, mas o que Oddone se esforça por nos transmitir é o facto de que o psicólogo do trabalho deve verdadeiramente modificar a organização e tudo o que encontra, utilizando aquilo que já há nos homens. O obstáculo (e a solução) é a linguagem. A linguagem que transforma as coisas incompreensíveis, o breakdown, em problemas.

164 O que interessa ao psicólogo é a cabeça do homem. Se queremos modificar o seu comportamento, não o podemos fazer com noções, com coisas que ele pode adquirir. $O$ que aprendemos nos livros temos que o transformar de tal maneira que o possamos utilizar no nosso comportamento profissional diário. 


\section{BIBLIOGRAFIA}

Clot, Y. (1999). Ivar Oddone : les instruments de l'action. Les territoires du travail, 3, 43-51.

Clot, Y. (2001). Editorial. Education permanente, 146, 7-15.

De Vincenti (1999). Ivar Oddone, intelectuel organique et chercheur hétérodoxe. Les territoires du travail, 3, 33-42.

Duarte C.(1998). L'impression flexografique : une contribution de l'analyse ergonomique du travail au sein d'un projet de développement des compétences. Performances Humaines et Techniques. nº hors série, 139-141.

Miller, G., Galanter, E. \& Pribam, K. (1960). Plans and the structure of behavior. New York : Holt, Rinehart and Winston.

Oddone, I. (1999). Psicologia dell'organizzazione della salute. In Psicologia della Salute, n. 1. Milano : Franco Agneli

Oddone, I. \& Re, A. (2000). Seminário apresentado na Faculdade de Psicologia e Ciências da Educação da Universidade do Porto sob o título Métodos em psicologia do trabalho. 10-11 Novembro. Porto : Não publicado.

Oddone, I., Re, A. \& Briante, G. (1981). Redécouvrir l'expérience ouvrière. Vers une autre psychologie du travail ?. Paris : Editions sociales.

Re, A. (1990). Psicologia e soggetto esperto. Torino : Tirrenia

Re, A. (1995). Ergonomia per psicologi. Lavoro cognitivo e nuove tecnologie. Milano : Raffaello Cortina Editore

\section{RESUMOS}

A partir da obra de Ivar Oddone, o artigo tenta reconstruir um percurso de investigação que nos parece ser útil, nos dias de hoje, para activar uma nova reflexão sobre como desenvolver uma psicologia do trabalho centrada no Homem que trabalha e na sua experiência. Num tom frontal e 
assumidamente informal, reflexos do caracter de Oddone e do teor não ritual dos documentos que estiveram na base deste texto, começar-se-á pelas primeiras reflexões e conceitos pelos quais Oddone se nos deu a conhecer : a redescoberta da experiência operária e da sua centralidade na transformação do trabalho. Derivar-se-ão questões de método e propostas de Oddone para a construção da experiência e para a exploração do seu potencial transformador, das quais se destacam as "instruções ao sósia". O texto desenvolver-se-á em torno dos conceitos de "linguagem", "sistema" e "interface", operacionalizados em situações concretas sobre as quais a equipa de Oddone foi reflectindo. Dá-se particular relevância ao seu Sistema de Informação Concreta (SIC), a partir do qual se procura lançar algumas reflexões e desafios a que a obra de Oddone nos convida.

A partir da obra de Ivar Oddone, el artículo intenta reconstruir un recorrido de investigación que nos parece ser útil, en los días de hoy, para activar otra vez una reflexión sobre como desarrollar una psicología laboral centrada en el Hombre que trabaja y en su experiencia. En un tono frontal y asumidamente informal, reflejos del carácter de Oddone y del tenor en el ritual de los documentos que han estado en la base de este texto, empezaremos por las primeras reflexiones y conceptos por los cuales Oddone se nos ha dado a conocer : el redescubrimiento de la experiencia operaria y de su centralidad en la transformación del trabajo. Derivarán cuestiones de método y propuestas de Oddone para la construcción de la experiencia y para la explotación de su potencial transformador, de las cuales se destacan las "instrucciones al sosia". El texto se desarrollará alrededor de los conceptos de "lenguaje", "sistema" e "interfaz", operativos en situaciones concretas sobre las cuales el equipo de Oddone ha ido reflexionando. Se da particular relevancia a su Sistema de Información Concreta (SIC), desde la cual se procura lanzar algunas reflexiones y retos a las que la obra de Oddone nos invita.

A partir de l'œuvre de Ivar Oddone, l'article tente de reconstruire un parcours de recherche. Il nous paraît en effet utile, aujourd'hui, de réactiver une réflexion à propos du développement d'une psychologie du travail centrée sur l'homme qui travaille et sur son expérience. Sur un ton qui assume son caractère frontal et informel à l'image de la personnalité de Oddone, mais également en raison du contenu non rituel des documents qui sont à la base de ce texte cet article présente d'abord les réflexions et les concepts par lesquels Oddone nous a été révélé : la redécouverte de l'expérience ouvrière et sa centralité dans la transformation du travail. A partir de là, sont traitées des questions de méthodes et des propositions de Oddone pour la construction de l'expérience et l'exploitation de son potentiel transformateur - et les “instructions au sosie " assument évidemment ici une importance particulière. Le texte s'articule ensuite autour des concepts de "langage ", "système " et "interface ", qui ont pris du sens dans les situations concrètes à propos desquelles l'équipe de Oddone a développé sa réflexion. On donne alors un relief particulier au Système d'Information Concrète (SIC), à partir duquel sont situés quelquesuns des défis auxquels l'œuvre de Oddone nous convie.

Anchored in the works of Ivar Oddone, this paper tries to reconstruct a research path with particular utility for activating a new reflection on how to develop a work psychology centred on the workingman and on his experience. In an upfront and informal style, reflecting Oddone's character and the "non-rituality" of the documents on which this paper is based, we will start at the first reflections and concepts through which we originally met Oddone : the rediscovery of workers' experience and its importance for the transformation of work itself. From that, we will derive matters of method as well as Oddone's proposals for experience construction and for the exploration of its transforming potential. In this regard the "instructions to a double" stand in a place of honour. The text will be developed around the concepts of "language", "system" and "interface", materialized in concrete situations on which Oddone's team has been reflecting. Particular relevance will be given to his System of Concrete Information (SIC, in its original 
acronym), from which we will try to set some reflections and challenges elicited by Oddone's works.

\section{ÍNDICE}

Mots-clés: expérience, langage, système, interface, SIC

Palavras-chave: experiência, linguagem, sistema, interface, SIC

Keywords: experience, language, system, interface, SIC

Palabras claves: experiencia, lenguaje, sistema, interfaz, SIC

\section{AUTORES}

\section{RICARDO VASCONCELOS}

Centro de Psicologia da Universidade do Porto - Faculdade de Psicologia e de Ciências da Educação da Universidade do Porto Rua do Campo Alegre, 1055, 4169-004 Porto, Portugal ricardo@fpce.up.pt

\section{MARIANNE LACOMBLEZ}

Centro de Psicologia da Universidade do Porto - Faculdade de Psicologia e de Ciências da Educação da Universidade do Porto Rua do Campo Alegre, 1055, 4169-004 Porto, Portugal lacomb@fpce.up.pt 